\section{Prevalence of Vitamin D Deficiency, Metabolic Syndrome and Association Between the Two in a South Asian Population}

Ramesh Reddy Allam ${ }^{1 *}$, Rashmi Pant ${ }^{1}$, Chengappa K Uthappa ${ }^{2}$, Manjunath Dinaker ${ }^{3}$, Ganesh Oruganti ${ }^{1,3}$ and Vijay V Yeldandi ${ }^{1,3,4}$

${ }^{1}$ Department of Health Research, SHARE India, Hyderabad, India

${ }^{2}$ The National Institute of Health (US), New Delhi Office, India

${ }^{3} G Y D$ Diagnostics and Reference Laboratories $(P)$ Ltd., Secunderabad, India

${ }^{4}$ College of Medicine, University of Illinois at Chicago, USA

*Corresponding author: Ramesh Reddy Allam, Department of Health Research, SHARE India, Hyderabad, India, Tel: 9959333632; E-mail: rameshallam@sharefoundations.org

Received date: March 21, 2018; Accepted date: April 23, 2018; Published date: April 30, 2018

Copyright: () 2018 Allam RR, et al. This is an open-access article distributed under the terms of the Creative Commons Attribution License, which permits unrestricted use, distribution, and reproduction in any medium, provided the original author and source are credited.

\begin{abstract}
Background: The etiological role of vitamin D in the metabolic syndrome among Asian Indians with good exposure to sunlight is not well understood. The objective of this was to estimate the prevalence of metabolic syndrome and vitamin $D$ deficiency and to determine the association between vitamin $D$ status and metabolic syndrome in an Asian Indian population from Hyderabad, India.

Methods: 299 normal individuals were randomly selected, for this cross sectional study, from individuals who voluntarily participated in a health camp. Anthropometric measures were taken along with 25 -hydroxyvitamin $D$, fasting blood glucose, complete lipid profiles were also assessed. Socio-demographic data such as sex, age, smoking status, physical activity and diet were also collected. Data was analyzed using t-tests and chi-square test of association.
\end{abstract}

Results: $81.6 \%$ had $25(\mathrm{OH}) \mathrm{D}$ deficiencies, $13.4 \%$ had insufficiency and $44 \%$ had metabolic syndrome. Females had lower levels of mean $25(\mathrm{OH}) \mathrm{D} 18.33 \pm 12.9 \mathrm{nmol} / \mathrm{l}$ as compared to males. $34.4 \%$ had $25(\mathrm{OH}) \mathrm{D}$ deficiency as well as metabolic syndrome. A significant $(p=0.02)$ association was observed between serum $25(\mathrm{OH}) \mathrm{D}$ and metabolic syndrome. Participants with $25(\mathrm{OH}) \mathrm{D}$ insufficiency had $4.6(p$-value $=0.023)$ times higher odds of metabolic syndrome versus those with $25(\mathrm{OH}) \mathrm{D}>100 \mathrm{nmol} / \mathrm{l}$, whereas those with deficiency had approximately 2 times higher odds.

Conclusion: Vitamin D deficiency has become a pervasive problem with implications for cardiovascular health across age and gender groups. Our research indicates that women are at a higher risk of having metabolic syndrome than men if they have deficiency or insufficiency of vitamin D. Timely translational research needs to develop the appropriate interventions to stem this.

Keywords: 25(OH)D; Metabolic syndrome; Metabolic risk; Lifestyle modification; Hypovitamonosis D

\section{Introduction}

Vitamin $\mathrm{D}$ is an important hormone for the functioning of the skeletal and non-skeletal systems of the body. Therefore the biochemistry and physiology of vitamin $\mathrm{D}$ in humans is extensively researched and documented [1,2]. Advances in medical diagnostics have made it possible to measure vitamin D levels more accurately and these are now best ascertained through serum concentration of 1,25 hydroxyvitamin $\mathrm{D}[3,4]$. The major source of vitamin $\mathrm{D}$ for the human body is through exposure to sunlight (UVB rays) leading to synthesis by the skin and then used for cell metabolism. Studies have shown low vitamin $\mathrm{D}$ levels in some populations despite adequate sunlight exposure [5].

Optimal levels of this steroid hormone in the body vary depending on the individual's geographical location, skin colour, age, sex and other factors [6,7]. Deficiency of the vitamin is associated with a multitude of conditions such as musculoskeletal, autoimmune and cardiovascular problems [8] and respiratory disorders [9]. Over the past decade vitamin $\mathrm{D}$ deficiency has been recognized as a widespread problem and the public health implications of this deficiency have become a cause of concern especially in low and middle income countries.

There is now also an active interest in understanding the role of vitamin $\mathrm{D}$ as a mediator or moderator of metabolic outcomes [10]. This stems in part from the fact that a greater prevalence of metabolic syndrome (MS), as defined by the International Diabetes Federation (IDF) [11], has been recognized increasingly across the world [12]. Studies in different settings have shown an association between vitamin $\mathrm{D}$, measured as serum $25(\mathrm{OH}) \mathrm{D}$ levels, and metabolic risk factors. However most of these studies have been in developed countries, at higher latitudes and primarily with urban populations [13-16].

To obtain better ethnic and geographic estimates of the relationship between serum $25(\mathrm{OH}) \mathrm{D}$ and metabolic syndrome including constituent metabolic risk outcomes, evidence from Asian populations 
living in latitudes with sufficient sunlight exposure needs to be evaluated. This study aims to add to the sparse evidence in this area $[17,18]$ with the objective to estimate the prevalence of MS as defined by the International Diabetes Federation [19] and to assess the association between vitamin D levels and metabolic syndrome in an Asian Indian population from Hyderabad in south India.

\section{Methods}

\section{Study design and sample size determination}

This is a cross-sectional study. The protocol of the study was approved by the institutional ethics committee of the Department of Health Research at SHARE INDIA prior to the start of the study, and written informed consent was obtained from all study participants.

The study sample consisted of $\mathrm{N}=299$ individuals in the age group of 18-75 years randomly selected from an ostensibly healthy population registered for a health awareness camp at Padmarao Nagar,

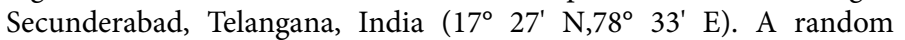
number generator was used to select subjects from among those registered for the health camp. The sample size was chosen so as to have at least $80 \%$ power to detect an odds ratio of 2 , at $5 \%$-level, for risk of metabolic syndrome among individuals with vitamin D deficiency- assuming a population prevalence of vitamin $\mathrm{D}$ deficiency of $50 \%$ [20].

Subjects were ostensibly healthy and were attending the camp for the purpose of routine health evaluation/screening and information motivation counseling campaign for lifestyle modifications. Pregnant women, lactating women, and those who did not fast for at least 10 hours prior to the camp and individuals who did not consent for the study were excluded. Individuals having history of thyroid dysfunction, on hormonal replacement therapy, on vitamin D supplementation, physically or mentally challenged and non-cooperative in nature were also excluded from the study.

\section{Measurements}

The research staff administered a structured questionnaire, which included questions on demography, smoking, diet, physical activity, and health history to all eligible participants. Details about smoking were obtained for type (cigarettes, bidis, and hookah), frequency (number of days), and years of smoking. Anthropometric measurements (height, weight, and waist circumference (WC)) and blood pressure were measured using standardized techniques [20] and calibrated equipment by trained research staff. Height and weight were measured using a stadiometer and a calibrated spring weighing machine. WC was measured using a non-expandable measuring tape.

Resting blood pressure with 5-min interval between each measurement was recorded using an automatic sphygmomanometer (Omron Healthcare). An average of up to two brachial systolic (SBP) and diastolic blood pressure (DBP) readings was used for the SBP and DBP values. A certified phlebotomist drew fasting (at least $10 \mathrm{hr}$ overnight) morning blood samples from the examinee's arm for the lipid (total cholesterol, HDL-C, and TGs), vitamin D and glucose assays. The samples were tested at a laboratory certified by the National Accreditation Board for testing and calibration Laboratories (NABL).

\section{Laboratory assays}

Venous blood was collected in evacuated tubes after an overnight fast of 8-12 hr (Vacuett, Greiner Bio-One GmbH, Vienna, Austria). Serum, EDTA, and plasma samples were separated by centrifugation within $1 \mathrm{hr}$ of sampling. Fasting venous plasma glucose was assayed using Dimension RXL Automated Clinical Chemistry Auto Analyzer (Dade Behring Inc., Newark, DE). Serum values were estimated using reagents and standards from Siemens and controls from BioRad Laboratories, Ltd. Estimation of HDL-C levels was carried out by the homogenous direct HDL-C method using reagents from Siemens and controls from Bio-Rad Laboratories, Ltd. All lipid assays were carried out on Dimension RXL Clinical Chemistry Auto Analyzer (Dade Behring Inc., Newark, DE).The serum concentration of 25(OH) D, regarded as the "gold standard" to measure the vitamin, was estimated using end point method [21]. LDL Cholesterol was calculated from the Friedewald equation.

\section{Metabolic syndrome criteria}

To identify the presence of MS, we used the IDF definition specified for a South Asian population [19]. Abdominal obesity as defined by WC of $\geq 94 \mathrm{~cm}$ for men and $\geq 80 \mathrm{~cm}$ for women is a mandatory feature of this definition which is specific to Asians. In addition, any of the two features as defined in NCEP ATP III [22] with a fasting glucose cutoff of $\geq 100$ was used to define MS by this criterion.

Vitamin D levels: Definition of deficiency was levels of 25(OH) D $<25 \mathrm{nmol} / \mathrm{l}$, insufficiency levels of $25<25(\mathrm{OH}) \mathrm{D} \leq 49.9 \mathrm{nmol} / \mathrm{l}$ and sufficiency if level of $25(\mathrm{OH}) \mathrm{D}>50 \mathrm{nmol} / \mathrm{l}[3]$.

In addition, individuals who reported current use of antihypertensive or statins or other-lipid lowering medications were classified as having high blood pressure and individuals currently taking insulin or oral hypoglycemic medication were classified as having diabetes. Individuals with a prior physician's diagnosis of hypertension or type 2 diabetes who did not report medication use were not classified as having high blood pressure or diabetes but were screened for high blood pressure and diabetes.

BMI was calculated by dividing weight by height squared $\left(\mathrm{kg} / \mathrm{m}^{2}\right)$. Weight categories were created based on the Indian government's consensus guidelines [23] which have reduced the diagnostic cutoffs for BMI for the Asian Indian population. The recommended categories used in this analysis were: Normal weight (BMI 18-22.9), overweight (BMI 23-24.9), and obese (BMI 25 or greater). Generalized obesity was defined as BMI greater than or equal to $25 \mathrm{~kg} / \mathrm{m}^{2}$, and central obesity was defined as WC greater or equal to $90 \mathrm{cms}$ for males and $80 \mathrm{cms}$ for females.

\section{Statistical analysis}

A descriptive analysis of risk factors is stratified by gender (Table 1). For each gender, a comparison between those determined to have MS versus those not having MS. The overall comparison of characteristics between the genders was done using t-tests (assuming unequal variances in groups) for quantitative variables for which test assumptions were met. Variables that were found to have a skewed distribution (triglycerides and fasting blood sugar), were compared using non-parametric Mann-Whitney U-test. 
Citation: $\quad$ Allam RR, Pant R, Uthappa CK, Dinaker M, Oruganti G, et al. (2018) Prevalence of Vitamin D Deficiency, Metabolic Syndrome and Association Between the Two in a South Asian Population. J Nutr Disorders Ther 8: 229. doi:10.4172/2161-0509.1000229

Page 3 of 6

\begin{tabular}{|c|c|c|c|c|c|c|c|c|}
\hline \multirow{2}{*}{$\begin{array}{l}\text { Risk Factors }^{*} \\
\text { Metabolic Syndrome }^{* *}\end{array}$} & \multicolumn{3}{|l|}{ Males ( $n=189$ ) } & \multicolumn{3}{|c|}{ Females $(n=110)$} & \multirow[t]{2}{*}{ Total (n=299) } & \multirow[t]{2}{*}{$p$-value } \\
\hline & No MS (122) & MS (67) & $p$-value ${ }^{\dagger}$ & No MS (46) & MS (64) & $p$-value ${ }^{t t}$ & & \\
\hline Age (years) & $47.2 \pm 14.7$ & $54 \pm 12.9$ & 0.0016 & $38.7 \pm 13$ & $47.5 \pm 13.6$ & 0.001 & $47.50 \pm 14.60$ & $<0.001$ \\
\hline Height (cms) & $161.7 \pm 7.56$ & $159.62 \pm 7.94$ & 0.079 & $147.9 \pm 9.2$ & $146.8 \pm 6.9$ & 0.48 & $156.04 \pm 10.21$ & $<0.001$ \\
\hline Weight (Kgs) & $68.3 \pm 12.4$ & $75.2 \pm 9.6$ & $<0.001$ & $59.6 \pm 11.2$ & $65.5 \pm 11.7$ & 0.013 & $68.03 \pm 12.414$ & $<0.001$ \\
\hline $\operatorname{BMI}\left(\mathrm{Kg} / \mathrm{m}^{2}\right)$ & $26.1 \pm 4.4$ & $29.6 \pm 3.9$ & $<0.001$ & $27.4 \pm 5.6$ & $30.5 \pm 5.6$ & 0.008 & $28.04 \pm 5.08$ & 0.0046 \\
\hline $\begin{array}{l}\text { Waist } \\
\text { circumference(cms) }\end{array}$ & $76.5 \pm 20.8$ & $104.7 \pm 37.6$ & $<0.001$ & $80.6 \pm 18.5$ & $92.3 \pm 7.1$ & $<0.0001$ & $86.91 \pm 26.10$ & 0.799 \\
\hline $\begin{array}{l}\text { Total } \\
(\mathrm{mg} / \mathrm{dL})\end{array}$ & $205.5(171,235)$ & 203(172,242) & 0.868 & $195.5(171,225)$ & $220(185.5,255)$ & 0.004 & $205(177,243)$ & $0.10^{* * *}$ \\
\hline Triglycerides (mg/dL) & $159(108,247)$ & $173(130,244)$ & 0.977 & $99(82,132)$ & $168.5(122.5,210)$ & $<0.0001$ & $150(107,219)$ & $<0.001^{* \star *}$ \\
\hline $\mathrm{HDL}(\mathrm{mg} / \mathrm{dL})$ & $36(29,44)$ & $36(31,43)$ & 0.539 & $49(37,57)$ & $40(34.5,46)$ & 0.0049 & $38(31,46)$ & $0.002^{* * *}$ \\
\hline LDL (mg/dL) & $127.5(97,158)$ & $123(95,163)$ & 0.78 & $122(111,151)$ & $143(115,179.5)$ & 0.17 & $128(103,160)$ & $0.008^{* * *}$ \\
\hline BP Systolic (mmHg) & $129.2 \pm 14.8$ & $137.2 \pm 14.6$ & $<0.001$ & $120.6 \pm 18.1$ & $129.8 \pm 14.4$ & 0.0036 & $129.84 \pm 15.94$ & $<0.001$ \\
\hline BP Diastolic (mmHg) & $79.7 \pm 10.3$ & $81.3 \pm 9.9$ & 0.302 & $75.2 \pm 6.6$ & $79.8 \pm 9.4$ & 0.0048 & $79.39 \pm 9.67$ & 0.042 \\
\hline $\begin{array}{l}\text { Fasting Blood Sugar } \\
(\mathrm{mg} / \mathrm{dL})\end{array}$ & $104(97,136)$ & $112(104,154)$ & 0.711 & $95(89,104)$ & $115(101.5,152)$ & $<0.0001$ & $107(97,136)$ & $0.345^{* * *}$ \\
\hline
\end{tabular}

*Values for continuous risk factors and outcomes are expressed as mean \pm standard deviations. For non-parametric variables values are reported as median (25th, 75th) percentile

${ }^{* *}$ As defined by International Diabetes Federation definition

${ }^{\dagger} \mathrm{p}$-values are for two-sided t- tests, assuming unequal variances, for comparison of means between males diagnosed with MS versus those not having MS and are significant at 0.05 level.

${ }^{\mathrm{H}} \mathrm{p}$-values are for two-sided t- tests, assuming unequal variances, for comparison of means between females diagnosed with MS versus those not having MS and are significant at 0.05 level.

${ }^{\mathrm{tt} \mathrm{p}}$ - values are for two-sided t- tests, assuming unequal variances, for comparison of means between males and females and are significant at 0.05 level.

${ }^{* * *} \mathrm{p}$-values are for non-parametric Mann-Whitney $\mathrm{U}$ test for comparison of medians

Table 1: Physical, biochemical and general characteristics of the study population.

The association between MS and vitamin D is tested using chisquare (Table 2). We also present the risk, using odds ratios and $95 \%$ confidence intervals, of MS in vitamin D deficient and insufficient subjects versus those with normal levels of $25(\mathrm{OH}) \mathrm{D}$. We calculated the prevalence of risk of MS and MS across all categories of vitamin D.
The lowest category represents the most deficient group. For each category, the prevalence of MS, abdominal adiposity, high triglycerides, hypoglycaemia and high blood pressure was calculated as a percentage (Table 3). All p-values presented are two tailed at $5 \%$ level.

\begin{tabular}{|c|c|c|c|c|c|}
\hline $\mathbf{N}(\%)$ & Metabolic & $\mathrm{ne}^{*}$ & & & \\
\hline Serum Vitamin D & No MS & MS & Total & $\mathrm{OR}^{\mathrm{b}}(95 \% \mathrm{Cl})$ & $p$-value $b$ \\
\hline Deficiency (<25 nmol//) & 142(58.2) & 102(41.8) & $244(81.6)$ & $1.9(0.6,6.4)$ & 0.255 \\
\hline Insufficiency (25-49.9 nmol//) & $15(37.5)$ & $25(62.5)$ & $40(13.4)$ & $4.6(1.2,17.0)$ & 0.023 \\
\hline Sufficiency (>=50 nmol/l) & $11(73.3)$ & $4(26.7)$ & 15(5) & 1 (reference) & \\
\hline Total & 168(55.9) & 131(44.1) & 299 & & \\
\hline$p$-value ${ }^{a}$ & 0.02 & & & & \\
\hline
\end{tabular}


Citation: Allam RR, Pant R, Uthappa CK, Dinaker M, Oruganti G, et al. (2018) Prevalence of Vitamin D Deficiency, Metabolic Syndrome and Association Between the Two in a South Asian Population. J Nutr Disorders Ther 8: 229. doi:10.4172/2161-0509.1000229

Page 4 of 6

${ }^{\mathrm{b}}$ Odds ratios and p-values from logistic regression models adjusted for age, sex, BMI, physical activity and diet.

*Definition of MS as given by International Diabetes Federation Guidelines for South Asians.

Table 2: Relationship between metabolic syndrome (MS) and serum 25-Hydroxyvitamin D.

\begin{tabular}{|c|c|c|c|c|c|c|}
\hline $\begin{array}{l}\text { Categories of } \\
\text { vitamin } \\
D(\mathrm{mmol} / \mathrm{l})\end{array}$ & $\begin{array}{l}\text { Metabolic } \\
\text { syndrome }\end{array}$ & Abdominal adiposity ${ }^{1}$ & Hyperglycaemia $^{2}$ & High triglyceride $^{3}$ & High $\mathrm{BP}^{4}$ & Low HDL-C ${ }^{5}$ \\
\hline Males $(n=189)$ & Prevalence (\%) & Prevalence (\%) & Prevalence (\%) & Prevalence (\%) & Prevalence (\%) & Prevalence (\%) \\
\hline Deficiency $(<25)$ & 33.6 & 37.4 & 47.1 & 52.9 & 50.9 & 64.5 \\
\hline $\begin{array}{l}\text { Insufficiency } \\
(25-49.9)\end{array}$ & 52.2 & 56.5 & 65.2 & 69.6 & 30.4 & 56.5 \\
\hline $\begin{array}{l}\text { Sufficiency } \\
(>49.9-150)\end{array}$ & 50 & 50 & 33.3 & 50 & 33.3 & 50 \\
\hline Toxicity $(>250)$ & 0 & 0 & 60 & 100 & 40 & 80 \\
\hline Ptrend & 0.138 & 0.13 & 0.774 & 0.287 & 0.674 & 0.897 \\
\hline \multicolumn{7}{|l|}{ Females $(n=110)$} \\
\hline Deficiency $(<25)$ & 56.2 & 100 & 44.9 & 34.8 & 24.7 & 68.5 \\
\hline $\begin{array}{l}\text { Insufficiency } \\
(25-49.9)\end{array}$ & 76.5 & 100 & 41.2 & 47.1 & 47.1 & 70.6 \\
\hline $\begin{array}{l}\text { Sufficiency } \\
(49.9-150)\end{array}$ & 25 & 100 & 25 & 25 & 0 & 75 \\
\hline Toxicity (>250) & 0 & 100 & 0 & 0 & 0 & 0 \\
\hline Ptrend & 0.978 & & 0.746 & 693 & 0.154 & 0.321 \\
\hline \multicolumn{7}{|c|}{$P_{\text {trend }}$ is $p$-value from a test of linear trend of proportions. } \\
\hline \multicolumn{7}{|c|}{${ }^{1}$ Abdominal adiposity is defined as waist circumference $>90 \mathrm{cms}$ (Males) and $>80 \mathrm{cms}$ (Females) } \\
\hline \multicolumn{7}{|c|}{${ }^{2} \mathrm{Hyperglycaemia}$ is defined as fasting blood sugar $>110 \mathrm{mg} / \mathrm{dl}$} \\
\hline \multicolumn{7}{|c|}{${ }^{3} \mathrm{High}$ triglyceride is defined as triglyceride $>150 \mathrm{mg} / \mathrm{dl}$} \\
\hline \multicolumn{7}{|c|}{${ }^{4} \mathrm{High} \mathrm{BP}$ is defined as Systolic BP $>130 \mathrm{mmHg}$ and diastolic $\mathrm{BP}>85 \mathrm{mmHg}$} \\
\hline${ }^{5}$ Low HDL-C is def & ined as $\mathrm{HDL}<40 \mathrm{r}$ & $/ \mathrm{dl}$ (Males) and $<50 \mathrm{mg} /$ & ales) & & & \\
\hline
\end{tabular}

Table 3: Prevalence of metabolic syndrome and its components across categories of vitamin D.

All analyses were done using STATA 12 (StataCorp. 2011. Stata Statistical Software: Release 12. College Station, TX: StataCorp LP).

\section{Results}

The study sample was pre-dominantly male $(63.2 \%, 189 / 299)$ and the mean age was $47.5 \pm 14.6$ years. Subjects with mean abdominal adiposity $(86.9 \pm 14.3 \mathrm{cms})$, median fasting blood sugar $107 \mathrm{mg} / \mathrm{dl}$ IQR- $(97,136)$ that is higher compared to normal waist circumference of $\leq 80 \mathrm{cms}$ and fasting blood sugar lower than $\leq 110 \mathrm{mg} / \mathrm{dl}$ respectively (Table 1). A significant difference was observed in anthropometric measures between males and females): height ( $\mathrm{p}$ $<0.0001)$, weight $(\mathrm{p}<0.0001)$ and BMI $(\mathrm{p}=0.004))$. Significant differences in lipid profiles were observed between males and females: triglycerides $(\mathrm{p}<0.001)$, HDL-C $(\mathrm{p}=0.002)$, LDL-C $(\mathrm{p}=0.008)$, diastolic BP $(\mathrm{p}=0.042)$ and systolic BP $(\mathrm{p}=0.0013)$.

Among males there was no significant difference in total cholesterol $(\mathrm{p}=0.87)$, HDL-C $(\mathrm{p}=0.54)$, LDL-C $(\mathrm{p}=0.78)$, triglycerides $(0.98)$, diastolic BP $(p=0.30)$ and fasting blood sugar $(p=0.71)$ between those with MS and those without MS (Table 1). Systolic blood pressure was significantly different in males with MS versus those without MS $(\mathrm{p}<0.001)$. In females, we found a significant difference $(\mathrm{p}<0.01)$ between those who had MS versus those who did not, in all lipid, blood pressure and fasting glucose measures except LDL-C $(\mathrm{p}=0.17)$.

The prevalence of MS in our sample was 44.1\% (131/299) (Table-2). Also $81.6 \%(244 / 299)$ of the participants had vitamin D deficiency $(25(\mathrm{OH}) \mathrm{D}<25 \mathrm{nmol} / \mathrm{l}), 13.4 \%$ (40/299) have insufficiency $(25<25(\mathrm{OH})$ $\mathrm{D} \leq 49.9 \mathrm{nmol} / \mathrm{l})$ and only $5 \%$ are identified as sufficient (15/299). 
Table 2 presents the bivariate association between vitamin $\mathrm{D}$ levels and MS. It explores the null hypothesis that there is no relationship between $25(\mathrm{OH}) \mathrm{D}$ and MS. It shows that $34.4 \%$ of the sample had 25 $(\mathrm{OH})$ D deficiency as well as MS. The association was significant $(\mathrm{p}=0.02)$ indicating that there is a relationship between MS and vitamin $\mathrm{D}$ that cannot be attributed to chance alone. After adjusting for age, sex, BMI, physical activity and diet, the risk (odds) of MS in vitamin $\mathrm{D}$ deficient subjects was found to be 1.9 times higher than that of subjects with normal levels and 4.6 times higher risk for those with insufficiency.

Prevalence of MS and associated components was calculated for different categories of vitamin D levels separately for males and females (Table 3). For males, the highest prevalence and metabolic risk (Prevalence: MS-52.2, abdominal adiposity-56.5, high triglycerides-69.6) was shown for subjects who had insufficiency in vitamin D. Males who had deficiency in vitamin $\mathrm{D}$ had high prevalence of High BP(50.9\%) and Low HDL-C (64.5\%). Females with vitamin D insufficiency had a high prevalence of MS (76.5\%), central obesity (100\%), high triglycerides and high BP (47.1\% each and low HDL-C $(70.5 \%)$. The $\mathrm{p}$-values for trend in prevalence (Ptrend) are greater than 0.05 , indicating there is no uniformly increasing or decreasing trend in prevalence of MS and its components across vitamin D categories.

\section{Discussion}

This paper explores the prevalence and relationship of two rapidly emerging conditions in the Indian sub-continent; metabolic syndrome and vitamin D deficiency. The prevalence of MS in India varies between $10-30 \%$ and the criteria used for defining MS are not uniform [24]. We used the International Diabetes Federation guidelines to determine presence of MS [14]. The overall prevalence of MS in the current study was $44 \%$. Like other studies our data also showed significant gender-specific differences. While some studies [25] show that males are at higher risk of MS as compared to females, our study like other studies in similar settings [24,26], showed higher (2.5 times) prevalence among females. Older subjects had higher odds of developing MS (Age> 46 had 1.9 times higher odds than Age $\leq 46$ ). Studies in other populations like Bali [27], Korea [28], Norway [29] have indicated an increasing prevalence of the MS with age.

Studies have reported a prevalence of $70-100 \%$ of vitamin D deficiency in the Indian subcontinent $[24,26]$ which is much higher than the prevalence range reported globally $30-50 \%[5,7,13]$. There is a continued debate in the published literature with respect to the optimum cut-off for 25(OH) D. For the purpose of maintaining uniformity, we used the categories used in studies based in South Asia $[17,18,26]$. Our study reports a prevalence of $25(\mathrm{OH}) \mathrm{D}<25 \mathrm{mnol} / \mathrm{l}$ as $82 \%$ and $25(\mathrm{OH}) \mathrm{D}<50 \mathrm{mnol} / \mathrm{l}$ as $95 \%$. This is despite the fact that the subjects belong to a low latitude area that have abundance of sunlight, hence sunlight exposure is expected to be adequate in our sample.

The key finding of this study augments the evidence of association of low vitamin D status and MS. The impact of poor vitamin D status on health with evidence of increased disease risk is steadily accumulating. Our study has shown a statistically significant relationship between MS and vitamin D with lower 25(OH) D levels showing higher odds of MS. A meta-analysis of 28 studies conducted between 1990 and 2009 [30] investigated the effects of vitamin D on the risk of CVD, diabetes and the metabolic syndrome. Eight of the studies reported prevalence of MS as the outcome. All of the eight studies reported a significant association between high $25(\mathrm{OH})$ D levels and reduced MS prevalence $(\mathrm{OR}=0.49,95 \% \mathrm{CI}$ : 0.38-0.64). Very few of these studies accounted for diet and physical activity in their models. In this study we assessed diet through a seven day recall and physical activity by the duration of intense physical work and exercise. We included diet, physical activity and smoking status in our model to make the association between MS and vitamin D more discriminating. We found that after adjusting for age, sex, smoking status, diet, physical activity and other metabolic risk factors, 25(OH)D deficiency was associated with a clinically high odds $(\mathrm{OR}=3.5)$ of having MS.

\section{Conclusion}

Our study indicates high prevalence of vitamin D deficiency among those with metabolic syndrome and women are especially vulnerable. The results from this study have shown a significant association between MS and vitamin D levels. However a proportionally greater risk of MS with the lowest levels of vitamin D as compared to mere insufficiency could not be demonstrated as a clear "dose response" relationship. Those with insufficiency were shown to be at five times greater risk and those with deficiency were at 2 times greater risk than those who were vitamin D sufficient. Perhaps insufficiency of the vitamin poses a greater risk of developing MS than deficiency due to other concomitant factors. Hence this evidence warrants further research in this area to identify better predicates of association. Policymakers should take note that vitamin D deficiency has become a pervasive problem with implications for cardiovascular health across age and gender groups. Timely translational research can be used to develop the appropriate interventions- such as food fortification, supplementation, improvements in environment and behavior change to mitigate potential problems attributable to Vitamin D deficiency.

\section{Limitations of the study}

This is a cross-sectional study and does not include long term follow-up to understand the causal pathway through which vitamin D deficiency may lead to metabolic syndrome or its components in Asian Indians. A longitudinal design would also have enabled the capture of seasonal variation in $25(\mathrm{OH}) \mathrm{D}$ levels by testing at multiple time points.

\section{Acknowledgements}

The authors wish to thank community members who spread awareness about our health camps.

\section{Competing Interests}

The authors declare that they have no financial or personal relationship(s) that may have inappropriately influenced them in writing this article.

\section{References}

1. Nicolaysen R, Eeg-Larsen N (1953) The biochemistry and physiology of vitamin D. Vitamins \& Hormones 11: 29-60.

2. Reichel H, Koeffler HP, Norman AW (1989) The role of the vitamin D endocrine system in health and disease. New England Journal of Medicine 320: 980-991.

3. Holick MF (2009) Vitamin D status: measurement, interpretation, and clinical application. Annals of Epidemiology 19: 73-78. 
Citation: Allam RR, Pant R, Uthappa CK, Dinaker M, Oruganti G, et al. (2018) Prevalence of Vitamin D Deficiency, Metabolic Syndrome and Association Between the Two in a South Asian Population. J Nutr Disorders Ther 8: 229. doi:10.4172/2161-0509.1000229

Page 6 of 6

4. Carter GD, Carter R, Jones J, Berry J (2004) How accurate are assays for 25-hydroxyvitamin D? Data from the international vitamin D external quality assessment scheme. Clinical Chemistry 50: 2195-2197.

5. Binkley N, Novotny R, Krueger D, Kawahara T, Daida YG, et al (2007) Low vitamin $\mathrm{D}$ status despite abundant sun exposure. The Journal of Clinical Endocrinology \& Metabolism 92: 2130-2135.

6. Clemens TL, Henderson SL, Adams JS, Holick MF (1982) Increased skin pigment reduces the capacity of skin to synthesize vitamin D3. The Lancet 319: 74-76.

7. Ginde AA, Liu MC, Camargo CA (2009) Demographic differences and trends of vitamin D insufficiency in the US population, 1988-2004 Archives of Internal Medicine 169: 626-632.

8. Souberbielle JC, Body JJ, Lappe JM, Plebani M, Shoenfeld Y, et al. (2010) Vitamin D and musculoskeletal health, cardiovascular disease, autoimmunity and cancer: Recommendations for clinical practice. Autoimmunity Reviews 9: 709-715.

9. Ginde AA, Mansbach JM, Camargo CA (2009) Vitamin D, respiratory infections, and asthma. Current Allergy and Asthma reports 9: 81-87.

10. Bikle D (2009) Non classic actions of vitamin D. The Journal of Clinical Endocrinology \& Metabolism 94: 26-34.

11. Alberti KG, Zimmet P, Shaw J (2005) The metabolic syndrome-a new worldwide definition. The Lancet 366: 1059-1062.

12. Wild SH, Byrne CD (2005) The global burden of the metabolic syndrome and its consequences for diabetes and cardiovascular disease. Metabolic Syndrome: 1-41.

13. Parikh SJ, Edelman M, Uwaifo GI, Freedman RJ, Semega-Janneh M, et al. (2004) The relationship between obesity and serum 1, 25-dihydroxy vitamin $\mathrm{D}$ concentrations in healthy adults. The Journal of Clinical Endocrinology \& Metabolism 89: 1196-1199.

14. Cheng S, Massaro JM, Fox CS, Larson MG, Keyes MJ, et al. (2010) Adiposity, Cardiometabolic risk, and vitamin D status: the Framingham Heart Study. Diabetes 59: 242-248.

15. Ford ES, Ajani UA, McGuire LC, Liu S (2005) Concentrations of serum vitamin D and the metabolic syndrome among US adults. Diabetes Care 28: 1228-1230.

16. Boucher BJ, Mannan N, Noonan K, Hales CN, Evans SJ (1995) Glucose intolerance and impairment of insulin secretion in relation to vitamin $\mathrm{D}$ deficiency in east London Asians. Diabetologia 38: 1239-1245.

17. Lu Y, Liu M, Pei Y (2015) Low levels of serum 25-hydroxyvitamin D and risk of metabolic syndrome in China. International Journal of Clinical and Experimental Medicine 8: 13790-13796.
18. Majumdar V, Nagaraja D, Christopher R (2011) Vitamin D status and metabolic syndrome in Asian Indians. International Journal of obesity 35 1131-1134.

19. The Metabolic Syndrome. International Diabetes Federation, 2006.

20. [No authors listed] Noncommunicable diseases and their risk factors.

21. Wagner D, Hanwell HE, Vieth R (2009) An evaluation of automated methods for measurement of serum 25-hydroxyvitamin D. Clinical Biochemistry 42: 1549-1556.

22. Heng D, Ma S, Lee JMJ, Tai BC, Mak KH, et al. (2006) Modification of the NCEP ATP III definitions of the metabolic syndrome for use in Asians identifies individuals at risk of ischemic heart disease. Atherosclerosis 186: 367-373.

23. Snehalatha C, Viswanathan V, Ramachandran A (2003) Cutoff values for normal anthropometric variables in Asian Indian adults. Diabetes care 26: $1380-1384$

24. Ritu, G (2014) Vitamin D deficiency in India: prevalence, causalities and interventions. Nutrients 6: 729-775.

25. Reis JP, von Mühlen D, Michos ED, Miller ER, Appel LJ, et al. (2009) Serum vitamin D, parathyroid hormone levels, and carotid atherosclerosis. Atherosclerosis 207: 585-590.

26. Majumdar V, Nagaraja D \& Christopher R (2011) Vitamin D status and metabolic syndrome in Asian Indians. International Journal of Obesity 35: 1131-1134

27. Suastika K, Dwipayana P, Saraswati IM, Kuswardhani T, Astika N, et al. (2011) Relationship between age and metabolic disorders in the population of Bali. Journal of Clinical Gerontology and Geriatrics 2: 47-52.

28. Park E, Kim J (2015) Gender-and age-specific prevalence of metabolic syndrome among Korean adults: analysis of the Fifth Korean National Health and Nutrition Examination Survey. J Cardiovascular Nursing 30: 256-266.

29. Hildrum B, Mykletun A, Hole T, Midthjell K, Dahl AA (2007) Agespecific prevalence of the metabolic syndrome defined by the International Diabetes Federation and the National Cholesterol Education Program: the Norwegian HUNT 2 study. BMC Public Health $7: 220$.

30. Parker J, Hashmi O, Dutton D, Mavrodaris A, Stranges S, et al. (2010) Levels of vitamin D and cardiometabolic disorders: systematic review and meta-analysis. Maturitas 65: 225-236. 